\title{
Analisis Kelayakan Investasi Kandang Tertutup pada Peternak Ayam Broiler Plasma PT Gema Usaha Ternak, Yogyakarta
}

\author{
Sutrisno Hadi Purnomo') dan Krishna Agung Santosa ${ }^{2)}$ \\ 1) Jurusan Peternakan, Fakultas Pertanian, Universitas Sebelas Maret, Surakarta \\ ${ }^{2)}$ Program Studi Ilmu Peternakan, Fakultas Peternakan, Universitas Gadjah Mada, \\ Yogyakarta \\ Email: trisno_purnomo@yahoo.com
}

\section{INTISARI}

Penelitian ini bertujuan untuk mengetahui kelayakan investasi kandang tertutup pada peternak ayam broiler plasma PT Gema Usaha Ternak ditinjau dari aspek keuangan. Penelitian ini dilakukan dengan pengambilan data primer dan sekunder. Data primer diperoleh dari peternak ayam broiler plasma PT Gema Usaha ternak, yaitu luas kandang, jumlah pemeliharaan ayam, biaya investasi, biaya operasional dan pemeliharaan serta penerimaan peternak. Data sekunder diperoleh dari PT Gema Usaha Ternak yaitu standar investasi kandang, biaya operasional dan pemeliharaan, harga-harga yang sedang berlaku dan data penerimaan peternak. Analisis keuangan yang dilakukan adalah net present value, profitability index, discounted payback period dan internal rate of return. Hasil analisis keuangan diuji sensitivitas dengan perubahan beberapa struktur pembiayaan. Pembuktian hipotesis menunjukkan bahwa investasi kandang tertutup peternak ayam broiler plasma PT Gema Usaha Ternak adalah layak secara aspek keuangan. Hasil analisis sensitivitas dengan beberapa perubahan struktur pembiayaan menunjukkan bahwa semakin tinggi penggunaan modal sendiri maka akan semakin layak. Hasil analisis aspek teknis dan teknologi, aspek pemasaran, aspek manajemen operasi dan aspek sosial lingkungan menunjukkan bahwa investasi kandang tertutup adalah layak.

Kata kunci : peternak ayam broiler, analisis kelayakan, analisis sensitivitas

\section{Feasibility Analysis of Closed House Investment of Broiler Farmers of Plasma PT Gema Usaha Ternak, Yogyakarta}

\begin{abstract}
This research is aiming at finding the feasibility of close house investment of broiler farmers of Plasma PT Gema Usaha Ternak from the financial point of view. The research was conducted by collecting primary and secondary data. The primary data, consisting of house size, number of birds, investment cost, operational and raising costs and farmer's revenue, were obtained from the broiler farmers of plasma PT Gema Usaha Ternak. The secondary data, consisting of standard house investment cost, operational and raising costs, the current prices, and farmers' revenue, were gained from PT Gema Usaha Ternak. Both primary and secondary data were then analyzed, observing the net present value, profitability index, discounted payback period and internal rate of return. The result of financial analysis was sensitively tested with changing some cost structures. The proving of the first hypothesis
\end{abstract}


revealed that close house investment were financially feasible. The result of sensitivity analysis with some changes in cost structure showed that the more the farmers used their own capital the more feasible it would be. The result of analysis on aspects of techniques and technology, marketing, operational management, and social-environment showed that close coop investment was feasible.

Key words : broiler farmers, feasibility analysis, sensitivity analysis

\section{PENDAHULUAN}

Dalam mengantisipasi tantangan ke depan, pembangunan bidang peternakan di Indonesia difokuskan pada usaha peningkatan pangan asal ternak, melalui pembangunan peternakan yang maju, tangguh, profesional dan efisien. Persaingan dunia usaha semakin kuat dan ketat baik antar industri ayam broiler sendiri maupun dengan industri komoditas peternakan lain, apalagi perdagangan bebas sebentar lagi akan diberlakukan sehingga semakin menambah tinggi tingkat persaingan. Oleh karena itu, agar suatu usaha peternakan dapat dipertahankan keberadaannya, maka peningkatan efisiensi melalui penggunaan teknologi harus terus ditingkatkan. Salah satu implementasi penggunaan teknologi dalam usaha peternakan adalah sistem perkandangan. Penggunaan teknologi kandang tertutup (close house) merupakan salah satu usaha untuk meningkatkan efisiensi bagi para peternak.

Sistem kandang tertutup banyak memiliki kelebihan disbanding kandang terbuka. Kelebihannya seperti situasi suhu dan kelembaban dalam kandang bisa diatur sehingga perubahan suhu dan kelembaban lebih diperkecil, kepadatan kandang lebih tinggi (12-14 ekor $\left./ \mathrm{m}^{2}\right)$ dibanding kandang terbuka $\quad\left(8-10 \quad\right.$ ekor $\left./ \mathrm{m}^{2}\right)$. Dampak lingkungan sosial dapat ditekan karena bau kotoran dan lalat bisa diminimalkan, serta beberapa keunggulan lainnya.

Sistem kandang tertutup adalah sistem kandang dengan kondisi udara tak bisa masuk kecuali masuk melalui inlet dan keluar melalui outlet yang sudah dibuat dalam suatu sistem ventilasi. Sistem kandang tertutup mempunyai tiga komponen utama yaitu : sistem ventilasi, sistem evaporasi dan sistem tirai. Sistem ventilasi digunakan sebagai outlet udara (saluran udara keluar), dengan komponen utama kipas angin. Sistem evaporasi sebagai inlet udara (saluran udara masuk) dengan komponen utama cooling net atau cooling pad. Sistem tirai digunakan sebagai penutup seluruh sisi kandang (samping kanan, kiri dan plafon), dilengkapi dengan sebuah peralatan buka dan tutup tirai.

Tujuan penggunaan kandang tertutup adalah memodifikasi lingkungan dalam kandang menjadi lebih nyaman sesuai dengan kebutuhan pertumbuhan ayam. Prinsip kerja sistem ini ada beberapa hal yaitu: 1). Mengeluarkan panas dari lingkungan, tubuh ayam dan litter; 2). Membuang uap air yang keluar dari pernafasan ayam; 3). Membatasi gas ammonia, karbondioksida dan hidrogen sulphida; 4). Menyediakan oksigen pada level yang optimum; 5). Membuat suhu dan kelembaban sesuai dengan kebutuhan ayam; 6). Mendorong pertumbuhan dan reproduksi optimum (Alchalabi, 2001; Anonimus, 2002).

Sistem kandang tertutup memiliki kendala pengembangan, yaitu biaya investasi kandang yang lebih tinggi dibanding kandang terbuka. Oleh karena itu, perlu pengkajian yang lebih pasti tentang kelayakan investasi, sehingga peternak plasma PT Gema Usaha Ternak maupun peternak-peternak lain yang berminat untuk investasi kandang tertutup bisa memprediksi investasi tersebut ke depan. 


\section{MATERI DAN METODE}

Penelitian ini menggunakan metode dasar deskriptif analitis yang disesuaikan dengan kepentingan pembuktian. Penelitian ini dilakukan di peternak plasma PT Gema Usaha Ternak yang menggunakan kandang tertutup (closed house) yang berada di wilayah DIY. Teknik yang digunakan dalam pengumpulan data, yaitu: 1). Wawancara, yaitu pengumpulan data dengan cara meminta keterangan melalui daftar pertanyaan yang telah dipersiapkan sebelumnya; 2). Pencatatan, yaitu pengumpulan data dengan cara mencatat data yang telah ada pada PT Gema Usaha Ternak; dan 3). Observasi, yaitu pengumpulan data dengan mengamati secara langsung obyek penelitian. Dalam penelitian ini digunakan data primer dan data sekunder. Data primer diperoleh langsung dari peternak plasma kandang tertutup dengan teknik wawancara. Data dari peternak plasma: data luas kandang, data jumlah pemeliharaan ayam, data biaya investasi kandang, data biaya operasional dan pemeliharaan serta data penerimaan peternak. Data sekunder diperoleh dari PT Gema Usaha Ternak, yaitu: data standar biaya investasi kandang, data biaya operasional dan pemeliharaan, data hargaharga yang sedang berlaku, data penerimaan peternak plasma.

\section{Analisis Data}

Untuk menguji hipotesis, yaitu secara aspek keuangan kandang tertutup yang layak diusahakan pada peternak ayam broiler plasma PT GUT, digunakan analisis keuangan net present value, profitability index, discounted payback period dan internal rate of return.

\section{Net Present Value (NPV)}

Selisih dari jumlah nilai sekarang proceed setelah dikalikan dengan discount factor, yang nilainya menggunakan suku bunga bank yang berlaku dengan investasi yang dikeluarkan. Apabila didapat nilai NPV yang positif, maka investasi dianggap menguntungkan. Dalam perhitungan NPV digunakan rumus :

$$
N P V=\sum_{t=0}^{n} \frac{B t}{(1+i)^{t}}-\sum_{t=0}^{n} \frac{C t}{(1+i)^{t}}
$$

\section{Profitability Index (PI)}

Selain dihitung NPV-nya, juga dihitung PI yaitu jumlah PV proceeds, dibagi PV investasinya. Jika PI lebih besar dari satu maka usaha diterima. Dalam perhitungan PI digunakan rumus :

$$
P I=\frac{\sum_{t=0}^{n} \frac{B t}{(1+i)^{t}}}{\sum_{t=0}^{n} \frac{C t}{(1+i)^{t}}}
$$

\section{Discounted Payback Period (discounted PP)}

Untuk mengetahui jangka waktu investasi yang dilakukan dapat dikembalikan dari perkiraan proceed (laba ditambah penyusutan) yang akan datang. Namun metode ini mempunyai kelemahan yaitu tidak memperhitungkan nilai sekarang, untuk mengatasi hal tersebut maka proceed dikalikan dengan discount factor. Dalam perhitungan discounted payback period digunakan rumus :

$$
\text { Investasi }
$$

\section{Disc. $\mathrm{PP}=\longrightarrow \quad \mathrm{x} 1$ thn \\ Disc. Proceed/thn}

Pengambilan kesimpulan adalah apabila discounted $P P$ lebih rendah dari umur ekonomis maka investasi diterima, namun apabila lebih tinggi dari umur ekonomis maka ditolak.

\section{Internal Rate of Return (IRR)}

Prinsip IRR adalah bagaimana menentukan discount rate yang mempersamakan present value of proceeds 
dengan investasinya, pada keadaan tersebut $\mathrm{NPV}=0$. Jika PV proceeds $>$ investasi maka gunakan discount factor lebih tinggi. Jika PV proceeds < investasi maka gunakan discount factor lebih rendah. Hal tersebut dilakukan sampai mendapatkan discount factor yang menjadikan PV proceeds = investasi atau $\mathrm{NPV}=0$. Dalam perhitungan IRR digunakan rumus :

$$
I R R=i^{\prime}+\frac{N P V^{\prime}}{N P V^{\prime}-N P V^{\prime \prime}}\left(i^{\prime \prime}-i^{\prime}\right)
$$

Hasil analisis keuangan juga dibandingkan antara aktual pada peternak plasma dengan standar rekomendasi dari PT GUT.

\section{Asumsi Dasar Analisis}

Analisis keuangan didasarkan pada beberapa asumsi dasar :

1. Besar luasan bangunan kandang adalah sama yaitu $\left(800 \mathrm{~m}^{2}\right)$, baik pada kandang standar maupun kandang aktual.

2. Struktur pembiayaan biaya investasi $0 \%$ biaya sendiri dan $100 \%$ pinjaman

3. Bunga pinjaman $18 \%$

4. Tarif pajak, sesuai Undang-undang No 11 tahun 1995 bahwa pajak penghasilan antara $0 \mathrm{~s} / \mathrm{d} 25$ juta adalah $10 \%$.

5. Discount factor adalah 15,30 (sesuai dengan tabel ).

6. Usia aset adalah 10 tahun.

7. Pemeliharaan peternak adalah selama 6 perioda per tahun.

8. Hasil produksi kandang tertutup menghasilkan konversi pakan 1,72 dan kandang terbuka 1,77 pada berat panen rata-rata $1,5 \mathrm{~kg}$ (standar PT. Gema Usaha Ternak)

9. Angka kematian 3\% untuk kandang tertutup (standar PT Gema Usaha Ternak).

\section{HASIL DAN PEMBAHASAN}

Perkiraan biaya dan penerimaan pada kandang standar dibandingkan dengan data aktual di lapangan yang digunakan sebagai dasar analisis keuangan. Setelah disesuaikan dengan discount factor, maka dibuat perhitungan proceed. Hasil proceed digunakan untuk analisis keuangan yaitu net present value, profitability index, discounted pay back period, dan internal rate of return. Hasil analisis keuangan tersebut diuji sensitivitas dalam berbagai struktur pembiayaan (capital rationing). Pembahasan aspek-aspek kelayakan lain yaitu aspek teknis dan teknologi, aspek pemasaran, aspek manajemen operasi, aspek sosial dan lingkungan dibahas secara kualitatif.

\section{Perkiraan Biaya}

1. Perkiraan Biaya Investasi

Biaya investasi yang dihitung adalah biaya bangunan kandang, peralatan pemeliharaan, biaya peralatan kandang tertutup, biaya instalasi listrik dan air. Sebelum diperhitungkan perkiraan biaya investasi, perlu diketahui parameter teknis pada kandang tertutup seperti terlihat pada Tabel 1.

2. Perkiraan Biaya Operasional dan Pemeliharaan

Perkiraan biaya operasional dan pemeliharaan pada kandang standar diperhitungkan selama satu perioda pemeliharaan lebih dahulu, kemudian dijumlahkan selama enam kali pemeliharaan per tahun seperti terlihat pada Tabel 3.

3. Penyusutan

Metoda penyusutan yang dipakai adalah metoda garis lurus tanpa nilai sisa, yaitu membagi total biaya investasi dengan umur ekonomi. Untuk kandang aktual perhitungan penyusutan diperoleh hasil pada Tabel 4 dibawah ini.

4. Biaya Modal

Analisis kelayakan ini diasumsikan bahwa proyek investasi dibiayai dengan dana yang bersumber dari pinjaman. Bunga dana pinjaman akan diperhitungkan dengan rata-rata beberapa tahun suku bunga pinjaman investasi dari bank pemerintah yang nilainya berkisar sebesar $18 \%$. Biaya modal untuk modal sendiri (cost of equity) diperhitungkan sebesar rata-rata 
suku bunga deposito pada bank pemerintah antara tahun 2001 sampai

tahun 2002, yaitu sebesar $14 \%$.

Tabel 1. Perbandingan Parameter Teknis Kandang Tertutup Standar dan Aktual

\begin{tabular}{lcc}
\hline & Standar* & Aktual** \\
\hline Jumlah ayam siap panen & 10.000 ekor & 9067 ekor \\
Luas kandang & $800 \mathrm{~m}^{2}$ & $800 \mathrm{~m}^{2}$ \\
Lantai kandang & tingkat 2 lantai & tingkat 2 lantai \\
Kepadatan ayam & 12,5 ekor $/ \mathrm{m}^{2}$ & $11,33 \mathrm{ekor} / \mathrm{m}^{2}$ \\
\hline
\end{tabular}

Keterangan : * Data survai PT Gema Usaha Ternak, tahun 2002

** Analisis data peternak plasma PT GUT, 2002

Tabel 2. Perincian Biaya Investasi untuk Kandang Tertutup

\begin{tabular}{lll}
\hline \hline & \multicolumn{1}{c}{ Standar* } & \multicolumn{1}{c}{ Aktual** } \\
\hline Bangunan kandang & Rp. $57.500 .000,00$ & Rp. $70.000 .000,00$ \\
Peralatan pemeliharaan & Rp. $20.875 .000,00$ & Rp. 30.000.000,00 \\
Peralatan kdg tertutup & Rp. $48.700 .000,00$ & Rp. 50.000.000,00 \\
Sarana listrik dan PAM & Rp. $6.000 .000,00$ & Rp. $3.750 .000,00$ \\
\hline Biaya total & Rp.133.075.000,00 & Rp.153.750.000,00 \\
\hline Keterangan : * Data survai PT Gema Usaha Ternak, tahun 2002 \\
** Analisis data peternak plasma PT GUT, 2002
\end{tabular}

Tabel 3. Perincian Biaya Operasional dan Pemeliharaan

\begin{tabular}{lrrrr}
\hline \hline & & Standar* & & Aktual** \\
\hline Sewa tanah & Rp. & $125.000,00$ & Rp. & $72.548,00$ \\
Gas LPG besar & Rp. & $840.000,00$ & Rp. & $488.909,00$ \\
Sekam & Rp. & $1.200 .000,00$ & Rp. & $697.878,00$ \\
Sanitasi (formalin) & Rp. & $250.000,00$ & Rp. & $145.884,00$ \\
Listrik dan PAM & Rp. & $2.500 .000,00$ & Rp. & $1.450 .955,00$ \\
Tenaga Kerja & Rp. & $1.200 .000,00$ & Rp. & $697.878,00$ \\
Obat lalat & & & & \\
Lain-lain & Rp. & $142.260,00$ & Rp. & $78.856,00$ \\
Biaya total & Rp. $6.790 .000,00$ & Rp. $3.942 .812,00$ \\
Biaya per tahun & Rp. $40.740 .000,00$ & Rp. $23.656 .870,00$ \\
\hline
\end{tabular}

Keterangan : * Data survai PT Gema Usaha Ternak, tahun 2002

** Analisis data peternak plasma PT GUT, 2002

Tabel 4. Hasil Perhitungan Biaya Penyusutan pada Kandang Standar dan Aktual

\begin{tabular}{lcc}
\hline \hline & Standar* & Aktual** $^{* *}$ \\
\hline Kandang tertutup & Rp. 13.307.500,00 & Rp. 11.375.000,00 \\
\hline
\end{tabular}

Keterangan : * Data survai PT Gema Usaha Ternak, tahun 2002

** Analisis data peternak plasma PT GUT, 2002

Tabel 5. Bunga Deposito dan Pinjaman Investasi pada Bank Pemerintah

\begin{tabular}{lcc}
\hline Tahun & Bunga deposito & Bunga pinjaman \\
\hline 2001 & 13,00 & 18,00 \\
2002 & 15,00 & 18,00 \\
\hline Rata-rata & 14,00 & 18,00 \\
\hline
\end{tabular}

Sumber : Statistik Ekonomi Indonesia. Bank Indonesia, tahun 2002 
5. Pajak

Pajak penghasilan sesuai dengan Undang-undang No 11 tahun 1995 tentang pajak penghasilan, yaitu :

1. Penghasilan sampai dengan $\mathrm{Rp}$ 25.000.000 dikenakan pajak $10 \%$.

2. Penghasilan $\mathrm{Rp} \quad 25.000 .000$ sampai $\mathrm{Rp} 50.000 .000$ dikenakan pajak $15 \%$.

3. Penghasilan lebih dari Rp 50.000.000 dikenakan pajak $30 \%$.

\section{Perkiraan Penerimaan}

Penerimaan yang diperoleh peternak yaitu dari hasil panen, insentif pemeliharaan dari perusahaan inti, penjualan pupuk kandang dan penjualan karung pakan. Dari hasil analisis diperoleh bahwa penerimaan peternak per periode adalah Rp 13.110.820,00 sehingga penerimaan per tahun (6 periode) adalah Rp 78.665.724,00. Perhitungan penerimaan pada kandang aktual dapat dilihat pada Tabel 6 .

Tabel 6. Rata-Rata Penerimaan Kandang Aktual per Peternak per Tahun

\begin{tabular}{lccc}
\hline \hline & $\begin{array}{c}\text { Luas kandang } \\
\left(\mathrm{m}^{2}\right)\end{array}$ & $\begin{array}{c}\text { Jumlah } \\
\text { ayam/tahun }\end{array}$ & $\begin{array}{c}\text { Penerimaan } \\
(\mathrm{Rp} .)\end{array}$ \\
\hline Kandang tertutup & 1000 & 68.000 & 86.948 .796 \\
& 800 & 54.402 & 69.561 .594 \\
\hline
\end{tabular}

Sumber : Analisis data peternak plasma PT GUT, 2002

Tabel 7. Penerimaan peternak per tahun pada kandang standar dan actual

\begin{tabular}{lcc}
\hline \hline & Standar* & Aktual** $^{* *}$ \\
\hline Kandang tertutup & Rp. 78.665.724,00 & Rp. 69.561.594
\end{tabular}

Keterangan : * Data survai PT Gema Usaha Ternak, tahun 2002

** Analisis data peternak plasma PT GUT, 2002

\section{Tingkat Bunga}

Perhitungan analisis keuangan ini menggunakan tingkat bunga sebesar biaya modal (cost of capital) yang besarnya ditentukan dari sumber dana yang digunakan. Perhitungan biaya modal menggunakan rata-rata tertimbang dengan modal sendiri adalah bunga deposito 14\% dan modal pinjaman adalah bunga pinjaman bank $18 \%$. Besarnya tingkat bunga untuk masing-masing struktur modal disajikan dalam Tabel 8.

Tabel 8. Tingkat Bunga dengan Variasi Struktur Pembiayaan Investasi

\begin{tabular}{cccc}
\hline \hline \multicolumn{2}{c}{ Struktur pembiayaan } & Biaya Modal & Tingkat bunga \\
\hline Modal sendiri & Modal pinjaman & Rata-rata tertimbang & (1-\%pajak)Biaya modal \\
\hline 100 & 0 & 14,00 & 11,90 \\
75 & 25 & 15,00 & 12,75 \\
50 & 50 & 16,00 & 13,60 \\
25 & 75 & 17,00 & 14,45 \\
0 & 100 & 18,00 & 15,30 \\
\hline
\end{tabular}

Sumber : Data Statistik Bank Indonesia, tahun 2002

\section{Perhitungan Proceed}

Setelah diperoleh hasil perhitungan analisis penerimaan maka dibuat perkiraan arus kas (cash flow) selama 10 tahun masa investasi. Arus kas tersebut dikurangkan dengan biaya operasi dan pemeliharaan, sehingga diperoleh pendapatan sebelum 
penyusutan, bunga dan pajak. Selanjutnya pendapatan tersebut dikurangkan dengan penyusutan dan bunga, sehingga diperoleh pendapatan sebelum pajak. Pendapatan sebelum pajak dikurangi dengan pajak, sehingga diperoleh pendapatan setelah pajak. Pendapatan setelah pajak digunakan sebagai dasar untuk perhitungan proceed. Rumus perhitungan proceed menurut Sartono (1991) adalah :

Proceed $=($ Pendapatan stlh pajak $)+$ penyusutan $+((1-\%$ pajak $) \mathrm{x}$ bunga)

Hasil perhitungan proceed selanjutnya digunakan sebagai dasar untuk analisis keuangan.

\section{Analisis Keuangan}

\section{Net Present Value (NPV)}

Dari perhitungan NPV untuk struktur pembiayaan $0 \%$ modal sendiri dan $100 \%$ modal pinjaman nampak bahwa dengan asumsi masa investasi 10 tahun, sedangkan struktur pembiayaan seluruhnya menggunakan dana pinjaman dengan bunga $18 \%$ didapat NPV pada kandang standar dan kandang aktual seperti tabel 9. Hasil tersebut menunjukkan bahwa investasi layak, karena NPV positif. Nilai NPV untuk kandang tertutup ternyata standar ternyata lebih besar daripada aktual.

\section{Profitability Index (PI)}

Hasil perhitungan PI pada kandang standar dan aktual dapat dilihat pada tabel 10. Tabel 10 tersebut menunjukkan bahwa baik kandang tertutup maupun terbuka layak untuk diusahakan, karena nilai PI lebih besar dari satu. Namun pada kenyataannya standar dari perusahaan masih memberikan profitabilitas lebih baik daripada aktual, hal ini menunjukkan kurang optimalnya hasil produksi pada kondisi aktual.

\section{Discounted Payback Period (Disc. PP)}

Hasil perhitungan disc. PP pada kandang terbuka maupun tertutup dapat dilihat pada Tabel 11. Investasi kandang tertutup akan kembali sebelum masa investasi berakhir. Pada kenyataannya standar perusahaan lebih baik daripada aktual, sehingga perlu peningkatan efisiensi pada proses produksi.

\section{Internal Rate of Return (IRR)}

Hasil perhitungan IRR untuk kandang standar maupun aktual dapat dilihat pada Tabel 12. Biaya modal untuk investasi adalah 18\%, hasil perhitungan IRR menunjukkan bahwa investasi pada kandang tertutup maupun terbuka layak diusahakan. Hal ini karena nilai IRR lebih besar dari $18 \%$ biaya modal (cost of capital). Dalam kenyataannya nilai IRR pada standar perusahaan lebih besar dibanding aktual kandang tertutup, hal ini juga menunjukkan perlu ditingkatkannya efisiensi produksi pada kandang tertutup.

Tabel 9. Hasil Perhitungan NPV pada Kandang Standar dan Aktual

\begin{tabular}{|c|c|c|}
\hline & Standar* & Aktual** \\
\hline Kandang tertutup & Rp. 62.640 .862 & Rp. 57.014.458 \\
\hline \multicolumn{3}{|c|}{$\begin{array}{r}\text { Keterangan : * Data survai PT Gema Usaha Ternak, tahun } 2002 \\
* * \text { Analisis data peternak plasma PT GUT, } 2002\end{array}$} \\
\hline \multicolumn{3}{|c|}{ Tabel 10. Hasil Perhitungan PI pada Kandang Standar dan Aktual } \\
\hline & Standar* & Aktual** \\
\hline Kandang tertutup & 1,47 & 1,37 \\
\hline
\end{tabular}

2002 
Tabel 11. Hasil Perhitungan Disc. PP untuk Kandang Standar dan Aktual

\begin{tabular}{|c|c|c|}
\hline & Standar* & Aktual** \\
\hline Kandang tertutup & 5 tahun; 1,2 bln & 5 tahun; 8,2 bln \\
\hline \multicolumn{3}{|c|}{$\begin{array}{r}\text { Keterangan : * Data survai PT Gema Usaha Ternak, tahun } 2002 \\
* * \text { Analisis data peternak plasma PT GUT, } 2002\end{array}$} \\
\hline \multicolumn{3}{|c|}{ Tabel 12. Hasil Perhitungan IRR pada Kandang Standar dan Aktual } \\
\hline & Standar* & Aktual** \\
\hline Kandang tertutup & 23,83 & 22,46 \\
\hline
\end{tabular}

Keterangan : * Data survai PT Gema Usaha Ternak, tahun 2002

** Analisis data peternak plasma PT GUT, 2002

\section{Analisis Sensitivitas}

Struktur pembiayaan diasumsikan dengan empat variasi pembiayaan yaitu modal sendiri $25 \%, 50 \%$, $75 \%$ dan $100 \%$. Kemudian variasi tersebut akan dilihat pengaruhnya terhadap NPV, PI, discounted payback period dan IRR. Hasil perhitungan setelah analisis sensitivitas bisa dilihat pada Tabel 13.

Dari tabel 13 dapat dijelaskan bahwa kenaikan penggunaan modal sendiri akan menaikkan nilai NPV, PI dan IRR, serta akan menurunkan nilai disc. PP. Hal ini disebabkan karena biaya bunga modal sendiri (cost of equity) yaitu bunga deposito lebih rendah (14\%) daripada bunga pinjaman (18\%), sehingga semakin besar struktur pembiayaan modal sendiri maka nilai NPV, PI, disc.PP dan IRR akan semakin besar.

Tabel 13. Hasil Perhitungan Analisis Keuangan pada Beberapa Struktur Pembiayaan

\begin{tabular}{|c|c|c|c|c|c|c|c|c|c|}
\hline \multirow{2}{*}{$\begin{array}{c}\text { Modal } \\
\text { Sendiri } \\
(\%)\end{array}$} & \multirow[b]{2}{*}{ Kandang } & \multicolumn{2}{|c|}{ NPV } & \multicolumn{2}{|c|}{ PI } & \multicolumn{2}{|c|}{ Disc. PP } & \multicolumn{2}{|c|}{ IRR } \\
\hline & & Std* & Aktual** & Std $^{*}$ & $\begin{array}{c}\text { Aktual } \\
* *\end{array}$ & Std* & Aktual** & Std* & $\begin{array}{c}\text { Aktual } \\
* *\end{array}$ \\
\hline 0 & Tertutup & 62.640 .862 & 57.014 .458 & 1,47 & 1,37 & $\begin{array}{l}5 \text { th; } 1,25 \\
\text { bl }\end{array}$ & $\begin{array}{l}5 \text { th; } 2,8 \\
\text { bl }\end{array}$ & 23,83 & 22,46 \\
\hline 25 & Tertutup & 68.979 .709 & 63.840 .700 & 1,52 & 1,42 & $\begin{array}{l}4 \text { th; } 11,5 \\
\text { bl }\end{array}$ & 5 th; $6 \mathrm{bl}$ & 24,01 & 22,74 \\
\hline 50 & Tertutup & 75.803 .431 & 71.189 .098 & 1,57 & 1,46 & $4 \mathrm{th} ; 10 \mathrm{bl}$ & $5 \mathrm{th} ; 4 \mathrm{bl}$ & 24,62 & 23,39 \\
\hline 75 & Tertutup & 82.985 .882 & 78.923 .808 & 1,62 & 1,51 & $\begin{array}{l}4 \text { th; } 8,5 \\
\text { bl }\end{array}$ & 5 th; $2 \mathrm{bl}$ & 25,25 & 24,05 \\
\hline 100 & Tertutup & 90.582 .249 & 87.104 .260 & 1,68 & 1,57 & $4 \mathrm{th} ; 7 \mathrm{bl}$ & 5 th & 25,88 & 24,71 \\
\hline
\end{tabular}

Keterangan : * Data survai PT Gema Usaha Ternak, tahun 2002

** Analisis data peternak plasma PT GUT, 2002

Hasil analisis keuangan antara standar perusahaan dan aktual di lapangan pada kandang tertutup dapat dilihat pada Tabel 14. Pembuktian hipotesis bahwa secara aspek keuangan investasi kandang tertutup pada peternak ayam broiler plasma PT GUT adalah layak diusahakan dapat dilihat pada Tabel 14, yaitu hasil NPV positif, nilai PI lebih besar dari 1, nilai disc. PP lebih cepat dari lama masa investasi (10 tahun) dan nilai IRR lebih besar dari bunga pinjaman (18\%). Kemudian rasio antara NPV dan biaya investasi pada Tabel 15 menunjukkan bahwa secara aktual pengembalian investasi pada kondisi aktual kandang tetutup masih dibawah standar perusahaan.

Analisis keuangan lain yang bisa digunakan untuk kandang tertutup adalah return on investment (ROI), yaitu diperoleh dari perbandingan antara total investasi dengan Pendapatan setelah pajak (EAT) kemudian dikalikan $100 \%$.

Hasil perhitungan pada Tabel 16 merupakan pendapatan setelah pajak. Hasil 
perhitungan ROI menunjukkan bahwa pengembalian investasi ternyata lebih tinggi pada kondisi kandang tertutup aktual.

Dalam kenyataannya mengapa hasil analisis keuangan masih dibawah standar yang diharapkan oleh perusahaan inti, hal ini karena peternak masih perlu memperhitungkan kembali biaya investasi yang lebih tinggi dibanding standar. Disamping itu, peningkatan efisiensi produksi harus dilakukan, hal ini karena peternak masih belum memiliki pengalaman memadai pada penggunaan kandang tertutup.

Tabel 14. Hasil Analisis Keuangan untuk Kandang Aktual dan Standar

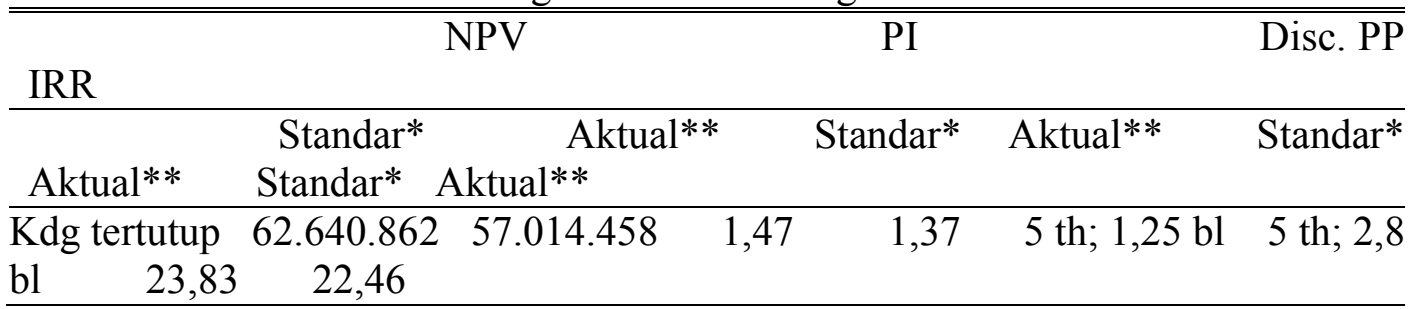

Keterangan : * Data survai PT Gema Usaha Ternak, tahun 2002

** Analisis data peternak plasma PT GUT, 2002

Tabel 15. Rasio antara NPV dan Biaya Investasi Standar dan Aktual

\begin{tabular}{lcc}
\hline & Standar* & Aktual** \\
\hline Investasi & 133.075 .000 & 153.750 .000 \\
NPV & 62.640 .862 & 57.014 .458 \\
Ratio & 0,48 & 0,37 \\
\hline
\end{tabular}

Keterangan : * Data survai PT Gema Usaha Ternak, tahun 2002

** Analisis data peternak plasma PT GUT, 2002

Tabel 16. Hasil Perhitungan ROI Kandang Standar dan Aktual

\begin{tabular}{lcc} 
& Standar* & Aktual** \\
\hline Investasi & 133.075 .000 & 153.750 .000 \\
EAT & 216.036 .000 & 255.756 .908 \\
ROI & 162 & 166 \\
\hline
\end{tabular}

Keterangan : * Data survai PT Gema Usaha Ternak, tahun 2002

** Analisis data peternak plasma PT GUT, 2002

Analisis Aspek-Aspek Kelayakan Lain

Aspek-aspek kelayakan lain yang diteliti secara kualitatif meliputi aspek teknis dan teknologi, aspek pemasaran, aspek manajemen operasi, aspek sosial dan lingkungan. Ditinjau dari aspek teknis dan teknologi, hasil produksi akan lebih baik (konversi pakan lebih rendah 0,05 dan angka kematian turun 3\%) dibanding kandang terbuka. Hal ini disebabkan temperatur dan kelembaban bisa diatur sesuai dengan kebutuhan ayam. Sedangkan pada kandang terbuka suhu dan kelembaban mengikuti lingkungan luar kandang. Ditinjau dari aspek pemasaran, peternak tidak akan kesulitan karena ayam hasil panen sama dengan ayam pada kandang terbuka dan penjualan sudah dikontrak dan ditangani oleh perusahaan inti. Ditinjau aspek manajemen operasi, diperlukan ketrampilan tenaga kerja yang lebih baik, namun jumlah tenaga kerja bisa dikurangi pada skala pemeliharaan yang besar. Ditinjau dari aspek sosial dan lingkungan, dampak lalat dan bau bisa dikendalikan. Hal ini sangat penting untuk saat ini, mengingat banyak kandang yang diprotes oleh masyarakat sekitar disebabkan bau kotoran dan lalat. 


\section{Pembiayaan Investasi Kandang tertutup}

Investasi kandang tertutup membutuhkan biaya yang lebih besar daripada kandang terbuka. Oleh karena itu bagi para peternak yang memilih pembiayaan dengan modal pinjaman, harus memiliki aset lain yang bisa digunakan sebagai jaminan pada pemberi pinjaman. Para peternak yang memilih pembiayaan dengan modal sendiri, tetapi modal kurang maka dapat bergabung beberapa peternak untuk investasi kandang tertutup. Para peternak yang cukup modal sendiri tidak akan kesulitan dalam pembiayaan.

\section{KESIMPULAN}

1. Berdasar aspek keuangan, hasil analisis NPV, PI, disc. PP dan IRR secara aktual pada kandang tertutup peternak ayam broiler plasma PT Gema Usaha Ternak layak untuk diusahakan.

2. Hasil analisis sensitivitas adalah semakin tinggi modal sendiri yang digunakan maka semakin besar nilai
NPV, PI, IRR dan semakin pendek nilai disc. PP.

3. Secara keseluruhan aspek teknis dan teknologi, aspek manajemen operasi, aspek pemasaran serta aspek sosial lingkungan kandang tertutup sangat layak digunakan.

\section{DAFTAR PUSTAKA}

Alchalabi, D. 2001. Triangle of Ventilation. Poultry International Magazine. December 2001 Ed. USA.

Anonimus, 2002. Sistem Closed House Efisiensi Menghadapi Globalisasi. Majalah Trobos, Edisi Februari 2002 : hal. 14-23, Jakarta.

Husnan, S. 1992. Manajemen Keuangan. Edisi 3. PT BPFE Fakultas Ekonomi Universitas Gadjah Mada, Yogyakarta.

Sartono, R.A. 1991. Manajemen Keuangan. Edisi 3. PT BPFE Fakultas Ekonomi Universitas Gadjah Mada, Yogyakarta. 